\title{
A Comparative Study of the Translation of Material Culture-loaded Words of Hongloumeng in the Light of Skopostheorie
}

\author{
$\mathrm{Ke} \mathrm{Yu}$ \\ School of Foreign Languages, Shanxi Normal University, Linfen 041000, China
}

\begin{abstract}
Hongloumeng, one of the masterpieces in China, a splendid history of classical literature, carries a large amount of Chinese traditional culture elements and culture-loaded words. This paper will apply skopos theory as the theoretical framework and analyze the translation of material culture-loaded words in Yang Xianyi and Gladys Yangs' translation of A Dream of Red Mansions and The Story of the Stone by David Hawkes. And then the author will try to list some representative culture-loaded words and reveal that how the skopos influences the translators' choice of translation methods and strategies in translation, and what effect or effects can be achieved. Some conclusions can be drawn.
\end{abstract}

Index Terms-Hongloumeng, Skopostheorie, culture-loaded words, translation strategies

\section{INTRODUCTION}

Language can help people pass information and promote their communication as well as spread culture globally. Translation is often regarded as the bridge for the communication between different languages and cultures. There are a large number of cultural factors in literary works, especially reflected by the culture-loaded words. Culture-loaded words could carry out language and culture information under different language backgrounds. Therefore, the translation of culture-loaded words in literary works can help target language readers get a better understanding of the culture elements of source language country, and promote cultural communication between different countries.

Hongloumeng is said to be a great encyclopedia of Chinese culture because it involves nearly every aspects of the culture. It is always full of charm to its readers. As it is such a great book that the translators have to tackle various translation problems arising from the cultural gaps in the translation process. While, translating Hongloumeng, one of the greatest realistic Chinese classic works, still remains an attractive and formidable venture for many ambitious translators. It has already been translated into different versions in about twenty-seven languages. The latest two translated texts are A Dream of Red Mansions by Yang Xianyi and his wife. Gladys Yang and The Story of the Stone by David Hawkes and his son-in-law John Minford respectively. Both of the two versions are very successful and are highly praised by the translators and translation theorists, most importantly, by the readers in china and abroad. Since then, many scholars and translators begin to compare and contrast those two English versions of Hongloumeng to find out the effective way in translation practice.

This study attempts to explain that the skopos theory influences the choice of translation strategy and to analyze the translation strategies used in translating the culture-loaded words in A Dream of Red Mansions. Under the influence of the skopos theory, the translators choose different translation strategies under different rules and achieve the translation goal by means of the readers' proper understanding of the source text through the translated version.

The practical significance of the study is to make the translators pay more attention to translation of culture-loaded words in the process of translation, and focus on the choice of translation strategies under different culture context in the light of the skopos theory. As choosing a proper translation strategy could help the target language readers get a better understanding of culture-loaded words in the source text, and it could also facilitate the culture transmission between different countries.

\section{LITERATURE REVIEW}

As culture-loaded words are embodied with a nation's cultural characteristics, the translation of them could be the reflection of a nation's traditional social culture and development. It is necessary to master the two languages and be familiar with the two cultures.

\section{A. Definition of Culture-loaded Words}

People from different countries form a quite different cultural tradition for the reason of different geographic position, living environment, religious belief, historical and cultural background, lifestyle, and thinking manner. When referring to lexical system, it is called culture-loaded words. For the definition of culture-loaded words, scholars defined it differently. 
For some famous foreign scholars, Mona Baker pointed that "The source language word may express a concept which is totally unknown in the target culture The concept in question may be abstract or concrete; it may relate to a religious belief, a social custom, or a type of food. Such concepts are often referred to as culture-specific" (Mona Baker, 2000). While Louis B. Salomon considered the culture-loaded words as "vocabulary blanks" and "semantic defaults" (Lado, 1957). Some other scholars also defined them as "key words" "culturally bound or culturally conditioned words".

In China, some scholars defined it differently. Hu Wenzhong offered that "Culture-loaded words refer to those in a specific culture sphere. They are the direct or indirect reflections of ethnical cultures" (Hu Wenzhong, 1999). Zhou Zhipei defined it as "The word (phrase) that is embedded with the meaning of a cultural particular to a certain socio-cultural community, whose referent is an unique thing or conception in the language in question, and therefore has no corresponding equivalent in other languages" (Zhou et al. , 1987).

Although there are so many definitions about culture-loaded words, all the definitions refer to the same kind of words which can express cultural meanings. Culture-loaded words are embedded with meaningful cultural connotations, and should be paid more attention when translating them from source text to target text.

\section{B. Studies on Material Culture-loaded Words Translation}

Culture-loaded words are encoded with the specific culture of a country or a nation. Referring to the translation of culture-loaded words, there are many experts and scholars who have done relevant researches in this field both in China and abroad.

1. Studies on material culture-loaded words translation abroad

With the development of globalization, the translation of culture-loaded words has been taken into account until mid-20th century. Many specialists and scholars have devoted themselves to the study of the translation of culture-loaded words. Eugene Nida put forth the theory "functiona /dynamic equivalence", which pointed out that the translator was responsible to shed light on the source culture information so as to help the target readers understand it better(Nida, 1964). Meanwhile, he raised a fresh concept "functional isomorphs", which could provide help to solve problems in the process of translating culture-loaded words (Nida, 1993). Lawrence Venuti focused on whether a translator encourages expressing unique characteristics of the source culture in the target language (Venuti, 1995). Meanwhile, he raised a "resistance" translation strategy to take the target readers bodily into the different flavor of the source culture and made them realize the divergent "cultural schema" in human's mind (Venuti, 1992).

In Snell-homby's opinion, an integrated translation approach should not confine to certain forms, but should consider translation from an overall perspective. She also held the view that the translators had better not only be proficient in the bilingual application but also live in a bicultural backdrop (Mary Snell-homby, Zuzana Jettmarova, Klaus Kaindl, 1995).

2. Studies on material culture-loaded words translation in China

For the study of translation of culture-loaded words, Chinese scholars are not laggard behind. At the same time, many experts recognize the similar questions about the translation of culture-loaded words and study on them. Wang Dongfeng, who put forth the concept of "cultural default", indicated that the absence of some cultural messages should be taken into consideration in the process of translation. He reckoned that impulsively employing domestication strategy to impose concepts and tastes of the target culture on the source culture was depriving the readers of their right to know (Wang, 1997).

In the opinion of Guo Jianzhong, domestication and foreignization were two important strategies in translating culture-loaded words, and these two strategies complemented each other. How to choose the translation strategy depended on the translation purpose and the target readership (Guo, 2000).

Wang Zuoliang pointed out the difficulties in cultural translation under stylistics in his book Translation: Experiments and Reflections. He put forward the view that in different genres of texts, different strategies should be applied to for the translation of culture-loaded words (Wang, 1984).

Some other Chinese scholars had also focused on the study of culture-loaded words. For example, Feng Yulv had written the book named Cultural Connotation of Words and Their Translation, Xu Wensheng and Zhu Zhanghua had published Cultural Connotation of Metaphorical Phase and Its Interaction with Translation, etc.

\section{Ш. THEORETICAL FRAMEWORK}

In this chapter, the theoretical basis of this paper---the skopos theory and two translation strategies will be talked about, which plays an important role in translating.

\section{A. The Skopos Theory}

The skopos theory is an important translation theory which was put forth and completed gradually in 1970s. It is the center of the functionalist translation theory which is firstly developed in Germany. The main representatives of this theory are K atharina Reiss. Hans J. Vermeer. Justa Holz-manttari, and Christiane Nord.

"Skopos" is a Greek word which means purpose or intention, and is defined as a translation theory by Hans J. Vermeer (Vermeer, 1978). As this theory is formed on the basis of function of both the source text and target text, it is 
called skopos theory. Skopos theory regards source texts as information provider, and provides a new viewpoint in translation. It plays a positive role in the process of translation. According to Vermeer, the skopos of translational acting determines the strategy for reaching the intended goal(Vermeer, 1978).

The core concepts of skopos theory include skopos, brief of translation, loyalty and adequacy. Skopos refers to the translation purpose, which is decided by the translator. The skopos will be different due to the translation action and translation process. Just as Nords' viewpoint of sender-oriented and reader-oriented. Therefore skopos is one of the core concepts of skopos theory. The brief of translation refers to the guidance of choosing translation method or strategy. The brief of translation will provide the idea on how the source text should be translated or what kind of translation should be applied. That is to say, the translator determines the translation skopos. Loyalty rule holds the view that the translator should respect the original author's communicative purpose in the translation process. It requires the translator to remain the original culture flavor in the translation process.

Skopos theory includes three rules: skopos rule, coherence rule and fidelity rule. Skopos rule, as the primate rule, holds that translation purpose determines the choice of translation strategy and translation strategy should provide service to translation purpose. Coherence rule emphasizes that target text should be adequately coherent to source text so as to make the readers understand the translation content. Fidelity rule requires the inter-textual coherence between source text and target text.

\section{B. Domestication and Foreignization}

Domestication and foreignization are two contrastive and complementary translation strategies. Schleiermacher points out that either the translator leaves the author in peace, as much as possible, and moves the reader toward him; or he leaves the reader in peace, as much as possible, and moves the author toward him (Venuti, 2004:101). The former refers to foreignization while the latter refers to domestication.

\section{Comparative Study of the Translation of Material Culture-loAded Words in the Light OF SKOPOSTHEORIE}

In this chapter, the author will approach the translation of the material culture-loaded words of Hongloumeng within the theoretical background of the skopostheorie and will strive to explore what kinds of methods and strategies are taken to solve the translation problems arising from the cultural gaps.

In this paper, the data are mainly collected from Hongloumeng by Cao Xueqin published by Sanqin Publishing House, from the first two volumes of A Dream of Red Mansions by Yang Xianyi and Gladys Yang (is hereinafter referred to as The Yangs), published by Foreign Languages Press, and from the first three volumes of The Story of the Stone by David Hawkes (is hereinafter referred to as Hawkes), published by Penguin Books.

Now we will turn to the material culture. All societies produce and exchange material goods so that people can feed, clothe, shelter, and otherwise provide for themselves. This system is known as the material culture. As is known to all, China and England culture differ greatly in terms of material culture. This poses various translation problems. The translation of Hongloumeng into English is especially the case since the modern English readers are unfamiliar with some of the materials produced and used in the Qing Dynasty, let alone to inform English readers with the translation. By analyzing the following examples, we will see what methods are employed by the Yangs and Hawkes who are assigned to different tasks, and whether their translations are adequate.

(1) 左边几上文王鼎匙箸香盒:右边几上汝窑美人解, 触内插着时鲜花卉, 并茗碗痰孟盒等物。

(chapter 5)

On the left-hand table were a tripod, spoons, chopsticks and an incense container; on the right one, a slender-waisted porcelain vase from the Juchow Kiln containing flowers then in season, as well as tea bowls and a spittoon.

(The Yangs)(p43, Vol I)

On the left-hand one was a small, square, four-legged ding, together with a bronze ladle, metal chopsticks, and an incense container. On the right-hand one was a narrow-waisted $\mathrm{Ru}$-ware imitation gu with a spray of fleshly cut flowers in it.

(Hawkes)(p96, Vol I)

The underlined phrases refer to the furnishings in ancient Chinese noble families. The expressions for the same furnishings cannot be found in English. That is to say, there exists a cultural gap between Chinese and English.

In the Yangs' translation, the intratextual coherence is basically achieved through literal translation since there is no difficult for the target addressees to understand the translation. However, the cultural peculiarity contained in the original has lost since the "tripod", "spoons" and "chopsticks" are culture-free things which can not provide the readers with the Chinese exotic flavors. In this sense, the translators fail to meet the requirement of the Skopos.

In Hawkes' translation, “鼎” is transliterated into “ding” with extra information to present readers with its size, form and external appearance. Additional information is also given in the translation of “匙” and “箸” to show readers such things are different from the metal ladle and wooden chopsticks they are familiar with. It is obvious that in his version, Hawkes conveys the cultural information embedded in the original. Judging from their respective Skoposi, the Yangs translation is not adequate, while Hawkes' is.

(2) 宝玉的意思即刻要叫人菏黄酒, 要山羊主血黎洞九来。

(chapter 31) 
He would have called someone at once to heat Shaohsing wine and fetch pills compounded with goats blood.

(The Yangs) (p451, VolI)

Bao-yu was all for calling one of the maids and getting her to heat some rice wine, so that Aroma could be given hot wine and Hainan kid's-blood pills.

(Hawkes)(p108, Vol. II)

“黄酒” is a kind of yellowish rice wine with low alcohol. “山羊血黎洞丸” is a kind of mixture of over ten kinds of herbal medicines with the goat's blood. These two are peculiar to China. Thus we cannot expect a literal translation of them which makes no sense to English readers.

In the Yangs' version, the translators interpret “黄酒” as "Shaohsing wine" which is unfaithful to the source text in terms of form. However, Shaoxing is famous for the production of “黄酒”. Then this translation may arouse readers' association. As for “山羊血黎洞丸”, the translators interpret it as "pills compounded with goat s blood” at the expense of its Chinese name but succeed in conveying its connotation. In this sense, both the intertextual coherence and intertextual coherence are achieved.

In the Hawkes' version, since intertextual coherence is subordinate to intratextual coherence, more efforts are made to achieve the latter. “黄酒” and “山羊血黎洞丸” are paraphrased into “some rice wine” and “Hainan Kid's-blood pills”, which helps readers by reducing the difficulty in understanding. In so doing, the translators' Skopos is fulfilled.

(3) 林黛玉笑道:“大节下怎么好好的哭起来? 难道是为争粽子吃争恼了不成?”

"What' all this crying during the festival?" asked Tai-yu mockingly, "Are you fighting for sticky rice dumplings?"

“Crying on a holiday? What's all this about? Have you been quarrelling over the rice-cakes?'

(The Yangs)(p455, VolI)

(Hawkes)(p113, VolI)

As a traditional food of Chinese people with a long history, “粽子” is not known to English readers. By comparing these two versions, we find the translators have no choice but to interpret “粽子” respectively as "sticky rice dumplings" and "the rice-cakes". Since dumplings and cakes are common food for English readers, they will have no difficulty in understanding. So far, the intratextual coherence in both the Yangs' version and the Hawkes' version has been achieved. In an attempt to achieve the maximum intertextual coherence, the translators use "sticky" as modifier to bring English readers closer to the real food. Comparatively speaking, the Yangs' version is more faithful to the original than the Hawkes' version since the former produces a more exact description of for readers' minds. However, given their different purposes. In the Yangs' version and The Hawkes' version, we should say both of them have fulfilled their tasks. In source text, the underlined Chinese phrases are valuable herbal medicines with a variety of functions.

In the Yangs' version, in order to achieve the intertextual coherence, the translators translate the first two medicines literally and interpret the last two according to their functions. Unfortunately, since the literal translation of the first two medicines makes no sense to English readers, it fails to convey the Chinese culture as the skopos required. Conversely, the free translation of the last two medicines informs English readers that ancient Chinese people cured diseases with such medicines. According to the Skopostheorie, the literal translation in the Yangs' version is inadequate translation, while the second part is adequate.

In Hawkes' version, the translator goes beyond keeping the literal meaning of these medicines to interpret their functions in their names. Strictly speaking, such translation is not quite faithful to the original, but the translator has succeeded in accomplishing the intratextual coherence required by the skopos in this translational action.

In the above examples, both the Yangs and Hawkes mainly paraphrase the culturally strange materials. When the Yangs combine the intertextual coherence with the intertextual coherence in their translation, they are able to fulfill their purpose well. However, guided by his Skopos, Hawkes puts more weight on the intertextual coherence to produce a target text meaningful and communicative to his readers.

Translating such words, just as Newmark has pointed out, usually adopts the transference, and in the case of Chinese "pinyin". Yang Xianyi reserves the source language color by using the ancient names which appear in the source text, while Hawks turns all of them into modern names in Chinese, which is comparatively familiar to the target readers.

(4) 正值王夫人与熙凤在一处拆金陵来的书信。

She found her and Hsi-feng discussing a letter from Chinling.

(chapter 3)

(The Yangs) (p51, Vol I)

They found her closeted with Wang Xi-feng, deep in discussion of a letter which had just arrived from Nanking.

当日地陷东南, 这东南有个姑苏城。

(Hawkes)(p109, Vol I) Present-day Soochow.

(The Yangs)(p6, Vol I)

Long, long ago the world was titled downwards towards the southeast; and in that lower-lying south-easterly part of the earth there is a city called Soochow.

(Hawkes)(p51-52, Vol I) 
For fear that modern westerners may be puzzled by the ancient name Chinling, he changed it to Nanking, which is Chinese famous city known to many westemers. However, this easy accessibility makes a part of source culture missing. Foreigners may assume that Nanking has always been called like this in the Chinese history. Yang reserves this historical color by translating as Chiming, thus sending a message that Nanking has other names in ancient China. In this case, we can not evaluate whose translation is better. Each of them caters for a type of readers. Yangs' translation is more accurate, thus may be more valuable for those specialists who want to explore the original culture. Hawks limited globalization is more pleasing to readers who just read the novel for fun.

From the examples above, we see that Yang tends to reverse the features of the source text by copying the original plus extra explanation in the form of footnotes globalization, while Hawkes always tries to avoid footnotes and adopts limited changing the original names to the modern names that are familiar to westerners. Each of the versions is suitable for a specific group of readers.

\section{CONCLUSION}

In this paper, the author has made a systematic research into the translation of material culture-loaded words in Hongloumeng under the framework of Skopostheorie. Through my research and study, the following major findings are revealed:

First of all, due to different translation skopos, the Yangs and David Hawkes adopted different translation strategies in translating culture-loaded words in Hongloumeng. Yang' s intentions were to (a) present Cao Xuegin's works as they are. (b) introduce and spread Chinese traditional culture and classic literature to the west. (c) serve as a help for the research of Hongloumeng and draw the readers' interest to the original text, spread Chinese traditional culture and classic literature to the west. Thus, in translating culture-loaded words, the Yangs adhered to the source language text strictly and tended to use the technique of foreignization-copying the original text, transliteration and extratextual explanation. The Yangs' source culture oriented attitude, which pays great attention to the intertextual coherence, is underlying their way of handling culture-loaded words of Hongloumeng.

In contrast, Hawkes purposes were to (a) faithfully transmit the thoughts and effects in a vivid and fluent language. (b) popularize Hongloumeng among the western readers with the focuses on readability and acceptability. So Hawkes was much more readers-oriented, domesticating most of culture-loaded words by means of assimilation, deletion and globalization. He also attached more importance to intratextual coherence.

Secondly, Skopostheorie can open up a new horizon for us in translation criticism. In translation, we should pay more attention to the study of Skopos since the Skopos of the translation determines the extent of equivalence.

Thirdly, Chinese translators should endeavor to transmit and preserve the cultural elements embedded in the source text in translating Chinese into English.

To sum up, this paper introduces a new perspective of looking at the issue of translation strategy, and provides a way to assess a translated text by examining whether the translators choice of a certain strategy fulfills his purpose. The author hopes that the detailed case study can give translators some suggestions on how to choose an appropriate translation strategy in their translation, which may be helpful for future research of Chinese-English literary translation. But due to the limited time and the shortage of related references, the research into the translation of material culture-loaded words of Hongloumeng is far from being complete. It is the writers' sincere wish that a thorough and deeper study of this subject can be made in the future.

\section{REFERENCES}

[1] Baker, Mona. (2000). In Other Words: A Coursebook on Translation. Beijing: Foreign Languages Teaching and Research Press.

[2] Cao Xueqin, Gao E. (1985). A Dream of Red Mansions. Beijing: People's Literature Publishing House.

[3] Hawkes David. (1973). The Story of the Stone (1vol). Britain: Penguin Books.

[4] Hawkes David. (1977). The Story of the Stone (2vols). Britain: Penguin Books.

[5] Hawkes David. (1980). The Story of the Stone (3vols). Britain: Penguin Books.

[6] Guo Jianhong. (1982). Cultural Factors in Translation: Alienation and Adaption. Foreign Language, 2, 12-18.

[7] Lado, Probert. (1957). Linguistic Across Culture. Ann Arbor: University of Michigan Press.

[8] Nida, Eugene A. (1964). Language in Culture and Society. Dell Hymes, Allied Publishers pvt., Ltd.

[9] Nida, Eugene A. (1993). Language, Culture and Translating. Shanghai: Shanghai Foreign Language Education Press.

[10] Qian Yaxu, Ji Mofang. (2011). A Quantitative Study of Translation Strategy of Material Culture-Loaded Words in Yang's A Dream of Red Mansions. Studies on "A Dream of Red Mansions", 6, 59-72.

[11] Snell-hornby, Mary, Zuzana Jettmarova \& Klaus Kaindl. (1995). Translation as Intercultural Communication: Selected Papers from the EST Congress, Prague. John Benjamins Publishing.

[12] Venuti, Laurence. (1992). Rethinking Translation---Discourse, Subjectivity, Ideology. London and New York: Routledge.

[13] Wang Dongfeng. (1997). Cultural Default and Coherence Structure in Translation. Foreign Language, 6, 55-60.

[14] Wang Jing. (2018). An Analysis of the Translation of Chinese Cultural Load Words From the Perspective of Corpus. Overseas English, 4, 47-48.

[15] Wang San. (2018). A Comparative Study on the English Translation of Material Culture-Loaded Words. Journal of Shanghai University of Electric Power, 34, 89-91.

[16] Wang Zuoliang. (1984). Cultural Comparison in Translation. Chinese Translators Journal, 1, 1-6. 
[17] Yang Liu. (2018). An Analysis of the Translation of Chinese Cultural Load Words From the Perspective of Translation Characteristics. English Teachers, 7, 118-121.

[18] Yang Xianyi and Gladys Yang. (1978). A Dream of Red Mansions(1vol). Beijing: Foreign Languages Press Peking.

[19] Yang Xianyi and Gladys Yang. (1978). A Dream of Red Mansions(2vols). Beijing: Foreign Languages Press Peking.

[20] Zhang Hongyan. (2000). The Translation of Culture-Loaded Words in Hongloumeng. Journal of Anhui University, 4, 60-63.

[21] Zhou Zhipei. (1987). Comparison and Translation between English and Chinese. Shanghai: East China University of Science and Technology Press.

KeYu was born in HongTong, Shanxi in 1993. She received her bachelor's degree in English from LvLiang University, Shanxi in 2017. She is currently a postgraduate studying for her master's degree and majoring in Foreign Linguistics and Applied Lingui stics in Shanxi Normal University. Her research interests included English learning strategies and Pedagogies. 